naturalists' trusts or the Otter Haven Project's work in this field. More too could have been said about the way in which the water authorities' schemes affect otter habitat, the opportunities which exist to reconcile the needs of land drainage and wildlife conservation, and the initiatives which some water authorities (for example, the Wessex and Welsh) have already taken. I am slightly uneasy about teaching the general public how to search for otter signs (chapter 10); increased disturbance was mentioned in chapter 9 as a possible reason for the otter's decline, and further disturbance by well-meaning otter-watchers may not be desirable.

Philip Wayre's achievements in breeding otters in captivity are unsurpassed, and he writes about his work with an infectious enthusiasm. This is a fascinating introduction to otters, but could have given more information about the animal's conservation.

ANGELA KING

\title{
A Wood in Ascam: a Study in Wetland Conservation, edited by A.H. Fitter and C.J. Smith. Ebor Press, York, and Yorkshire Naturalists’ Trust, £4.95.
}

This small volume records the history and present ecology of 'the Wicken Fen of the North', the 100-acre Askham Bog just two miles from the centre of York. The first hundred pages are occupied by chapters dealing with the history of the area, its habitats and its flora, with selected animal groups and with current management. None of the chapters dealing with the flora and fauna attempts to be comprehensive; instead special attention is paid to groups or species of particular interest. The chapters on history, habitats and plants contain much astute observation and summaries of a considerable amount of recent research. The final third of the book is given over to appendices listing species recorded on the bog. Unfortunately there is no index.

The book was produced to commemorate the centenary of the publication, in 1879 , of the first systematic account of the biology of the area. The desire to meet this deadline is perhaps reflected in a degree of repetition, some roughness of style and poor collation between some sections. Immediate contrasts suggest themselves between this book and the monographs on Hayley Wood and Monk's Wood, both of which also seem to be aimed at the interested amateur and the professional. The smaller size of the present volume inevitably means less complete coverage, while the general standard of production, especially of figures, is lower. Within such limitations however this book compares quite favourably to the other two studies.

Despite some weaknesses the book will be of great interest to many conservationists, both as a record of a particular site and as an impressive indication of the observation and research needed to understand and adequately manage nature reserves.

H.J. HARVEY

\section{Population Ecology of Raptors, by Ian Newton. Poyser, $£ 10.80$.}

By synthesising studies on diurnal birds of prey world-wide this book fills a gap in the review literature. Its 18 chapters range from mating systems, dispersion, aspects of breeding and movements (including migration), through to conservation management and captive rearing. The pesticide problem and other anthropogenic issues are given three chapters - appropriately, since the identification, analysis, and amelioration of the pesticide problem has become something of a classic success for the role of science in wildlife management. Photographs are well chosen and reproduced, and a fine line drawing by Jim Gammie heads each chapter. Tables are relegated to an appendix. The style is highly readable as well as scholarly.

After a short introduction to raptor biology, the discussion begins with sex ratios and dimorphism. Breeding density - conventionally the focus of population ecology - is dealt with as early as chapter 3 . The central theme concerns the role of food, and by the final chapter it is not surprising to read the "overall conclusion that, in the absence of human intervention, almost every aspect of the natural population ecology of a given 